\title{
El movimiento anarcopunk de Guadalajara. Una apuesta por resistir-existir contra y más allá del Estado/capital
}

\section{Hugo Marcelo Sandoval Vargas}

En los conciertos, autogestión, nuestro trabajo, autogestión. La distribución, autogestión, anarcopunk, hazlo tú mismo.

Sin Dios, Autogestión.

A pesar de estar hundidos en el fango, todavía hay quien se atreve a descorrer el velo de las sombras, aspirar a alcanzar las estrellas, elevar los ojos y el pensamiento hacia el infinito. A pesar de estar hundidos en el fango, todavía hay quien se atreve a: Resistir y Existir.

Fallas del Sistema, Poema.

$\mathrm{L}$ a vida dentro del Estado y el capital es un continuo y es repetición, es ir con la corriente reproduciendo relaciones sociales de explotación y dominación machistas, jerárquicas, xenofóbicas, autoritarias, etc.; es mantener la clausura de la institución heterónoma y su magma de significaciones imaginarias sociales. La opción ética y política por ser-estar contra y más allá del Estado y el capital se da a saltos y de manera contradictoria. Son una pluralidad y heterogeneidad de historias, imágenes-testimonios con marcas y grietas. Cada experiencia, cada momento, cada sujeto individual y colectivo se mueve en la incertidumbre y desde el tiempo discontinuo.
Para vivir en las sociedades divididas entre dominadores y dominados, representantes y ciudadanos, basta la repetición y ver a las instituciones como externas a nosotros, creer en el progreso. Para vivir contra y más allá del Estado y el capital es necesaria una labor de creación e imaginación cotidianas, no dejar de moverse - auto-alterarse- y poner en cuestión a cada momento lo que construimos para hacernos sabedores de que todos los días instituimos el mundo social, aquí y ahora. Por ese motivo, la historia de aquellos que deciden romper y cuestionarse la explotación y la dominación es incompleta, deshilvanada. Son experiencias que muestran imágenes-testimonios de indeterminación y

\footnotetext{
The Anarcho-Punk Movement in Guadalajara.A Bet on Resist and Exist Against and Beyond the State and the Capital

Hugo Marcelo Sandoval Vargas: Centro de Estudios y Documentación Anarquista "Francisco Zalacosta", Guadalajara, Jalisco, México msandovalv@hotmail.com
}

Desacatos, núm. 37, septiembre-diciembre 2011, pp. 183-190 
conflicto, de crisis e insubordinación, de rebeldía y autonomía.

La imagen-testimonio del movimiento anarcopunk de Guadalajara es también una historia rota, parchada, con picos y cicatrices, pero al mismo tiempo plagada de tiempos vividos. Comienza en 1983 en los barrios de la zona metropolitana de Guadalajara con las primeras bandas de música y afinidades punks, con la resistencia cotidiana en guerra contra la autoridad representada por los padres, los maestros, la policía, los grupos estudiantiles paramilitares y los curas. El movimiento emergió en Londres bajo el grito: “ ¡No hay futuro!”, y los primeros acordes de la música punk -que podían significar todo menos la autodestrucción que la moda capitalista quiso endilgarles - irrumpieron en los barrios marginales entre los hijos de obreros, migrantes, desocupados y empleados de clase media. Debemos remontarnos a los años sesenta con la insurrección del mayo francés que trastocó las formas estatistas de hacer política de los partidos y los sindicatos, con el movimiento beat que vomitó a través de sus letras la cultura conformista y burguesa de la sociedad occidental, con el situacionismo que nos recordó que la revolución es un acto creativo y lúdico en el aquí y ahora, con los jóvenes hippies que se negaron a ir a morir - como sus padres en Corea- en la campaña de conquista que emprendió Estados Unidos después de la Segunda Guerra Mundial. Puede considerarse otro inicio con el anti-arte de los movimientos dadaísta y surrealista que irrumpieron en el periodo de entreguerras en Europa - en un momento de crisis y catástrofe en el que el capitalismo decidió llevar a la muerte a millones de personas para seguir reproduciéndose, y la izquierda estatista esperaba la salvación del dios trabajo y el dios progreso-. Mediante el shock, la ironía y la insubordinación, el dadaísmo y el surrealismo destrozaron dogmas, cuestionaron las verdades del racionalismo y negaron la repetición.

Habría que tener en cuenta que a mediados del siglo XIX el naciente movimiento anarquista desplegó luchas obreras, campesinas e indígenas por la autogestión y la auto-organización de la sociedad desde la acción directa y descentralizada, contra la dominación y la explotación. El movimiento se forja en cada momento de conflicto social, toma la forma de lo que es afín a cada sujeto social: desde el artesanado, la forma de sociedades mutualistas; desde los obreros, la de sindicatos revolucionarios y anarquistas; desde los campesinos e indígenas, la forma-comunidad y la insurrección; desde los jóvenes punks, la forma de bandas de música y grupos de afinidad.

\section{LA IRRUPCIÓN DEL PUNK}

El punk se hizo visible a finales de la década de 1970 y se extendió rápidamente por Europa, América y varios países de Asia. Es un movimiento contracultural forjado en los márgenes de la juventud sin futuro cuando el neoliberalismo se impuso como la nueva forma de organizar el mundo y emprendió una guerra mundial contra la humanidad. Es una constelación de experiencias y significaciones que emerge haciendo una crítica a la cultura burguesa, como una ruptura con las formas dominantes de hacer arte, contra todo aquello que se convierte en mercancía y moda para venderse en el mercado capitalista. Irrumpe contra la sociedad conformista y conservadora.

Los jóvenes punks reniegan de sus padres, que han dejado de luchar por un mundo diferente del modelo familiar hegemónico, donde sólo se puede aspirar a tener una casa y un automóvil. El punk provoca un shock, trastoca la vida cotidiana y desacomoda el paisaje urbano mediante su hacer-ser en las calles, niega las formas dominantes de hacer política - esas donde los adultos se dedican a hacer partidos políticos y sindicatos reformistas para dirigir y representar a los demás- que forman personas que aspiran a ser profesionales y expertos en la política, a hacerse del control del poder y ser los nuevos amos que dicten los destinos de la sociedad. El punk se planteó una política diferente, no quiso competir ni ganarle espacios a la política institucionalizada, se desplegó de modo descentralizado mediante el arte y la música: la ropa, los fanzines, las canciones y el cuerpo 
creaban espacios de encuentro e intercambio horizontal de saberes, los grupos de afinidad se basaban en la amistad y las relaciones cara a cara del barrio.

Por ello, el enunciado: “¡Hazlo tú mismo!”, la postura ética y política que se instituyó en el punk para vivir la autogestión aquí y ahora, desde el día a día, para construir formas de sobrevivencia, trabajo y comunicación diferentes, fuera y contra el mercado, permitió el encuentro con una historia y una forma de hacer política que la autogestión y la vida sin Estado ni capital propusieron desde el siglo xIx: el anarquismo. En México, el punk se hizo presente en los inicios de la década de 1980. La tensión entre cosificarse en una moda y una mercancía o mantener su carácter de ruptura y shock era algo cotidiano. El ruido ensordecedor de lo que se mostraba en los medios imponía una tendencia como pose pasajera que podía comprarse en una tienda. Sin embargo, las redes subterráneas por las que viaja la contracultura punk por todo el mundo instituyeron formas de comunicación, distribución y difusión horizontales, cara a cara, en los barrios y las escuelas, por medio del envío de cartas y paquetes de una ciudad a otra, de un país a otro y de un continente a otro.

Las letras de las canciones de las primeras bandas de punk se configuraron desde una política pesimista y de negación, gritaban su rechazo al hostigamiento policial en los barrios, su inconformismo con las formas de educación autoritaria y alienante, contra todo lo que padecían día a día. El punk se hacía visible como choque y ruptura, y su presencia generaba tensión hasta que desplegó su política de complicidad en situaciones de crisis y forjó la solidaridad al interior del movimiento hacia los barrios. Después del terremoto de 1985 en la ciudad de México, se organizó con la gente para rescatar a las personas que habían quedado atrapadas entre los escombros, participó en la reconstrucción de las casas y en la recolección de alimentos. En las explosiones del 22 de abril de 1992 en la ciudad de Guadalajara, creó el colectivo Resistencia a Barreras Impuestas-Anarquistas (RABIA) para promover iniciativas de solidaridad con los damnificados.
Anti-arte y contracultura, ¡hazlo tú mismo! y un horizonte ético-político de vida donde resistir es existir son el suelo donde germinó el movimiento anarcopunk en Guadalajara. La organización autogestiva de conciertos -en espacios improvisados y ocupados temporalmente: casas, baldíos, etc.-, los vínculos comunitarios creados en las calles, la creación de una estética elaborada por el propio movimiento - utilizando la serigrafía como herramienta-, la construcción de medios de información y difusión propios - fanzines y distribuidoras autogestivas de materiales- dieron lugar a relaciones sociales, vínculos y formas de hacer que exigían congruencia entre medios y fines. Si se está luchando por la autonomía, ésta sólo puede instituirse a través de la autogestión y la acción directa.

\section{UNA POLÍTICA ORGANIZATIVA LIBERTARIA}

Durante cien años, de 1840 a 1940, el anarquismo se instituyó en el mundo del trabajo, desde las luchas obreras, campesinas e indígenas. El impulso que alcanzaron los procesos de insubordinación y revolución de los trabajadores del campo y la ciudad en ese momento generó una de las crisis más profundas en el capitalismo - tal vez comparable con la actual, que también fue producto de los momentos de lucha y rebelión-. El capitalismo respondió con dos guerras mundiales, el Estado de bienestar y una Guerra Fría. Esta política de contención, control, represión y guerra detuvo durante algunas décadas la oleada revolucionaria generada por los trabajadores, pues las formas estatistas de hacer política se instituyeron como hegemónicas $-\mathrm{y}$ fueron reproducidas por izquierdas y derechas-, aunque se quiebran en momentos como 1968, 1977 y 1994, cuando los jóvenes, los indígenas, las mujeres y los estudiantes deciden autogestionar su vida, y por tanto sus horizontes ético-políticos y las formas de hacer las luchas.

La imagen-testimonio del movimiento anarcopunk de Guadalajara nos muestra a un sujeto social que de 1990 y hasta la actualidad ha intentado mantenerse 
en movimiento y transformación de acuerdo con sus necesidades y su horizonte libertario. Se ha negado a dejarse dirigir y no ha aspirado a dirigir a nadie. La construcción de su política organizativa libertaria se ha construido a partir de procesos discontinuos de auto-formación política y de la experiencia que ha adquirido en la práctica diaria, de la condensación de saberes que se van acumulando con cada iniciativa, cada represión, cada proyecto, cada frustración, cada complicidad.

En lo local, durante los primeros años de la década de 1990 se crearon los colectivos anarcopunks. Las afinidades de los barrios y las bandas de música punk adquirieron una nueva dimensión al crearse la conexión entre anarquismo y punk. Con los aspectos de complicidad y solidaridad por los vínculos de amistad, se generaron iniciativas de resistencia y organización para encontrarse con otras luchas y movimientos.

La Unión Cívica Antiautoritaria (UCA) — creada en 1992- sigue con las iniciativas contraculturales, como conciertos, pero trata de difundir el horizonte sente. La UCA es el primer colectivo que cor con una labor de auto-formación política mediante círculos de estudio. No recurrieron a expertos, nadie dictó la línea correcta. A partir de una actitud de intuición y búsqueda se hicieron de saberes anarquistas, de liberación animal, etc. Esto se reflejó en las letras con un contenido libertario que sirvieron como medio de agitación y protesta para la banda $\mathrm{Fa}$ llas del Sistema.

El Grupo Anarquista Apoyo Mutuo empezó en 1995 a actualizar el anarquismo al situarlo en el contexto local desde lo que el propio movimiento era, por eso nunca lo separó de la contracultura. El movimiento anarcopunk se veía como parte de la propia historia del movimiento libertario. Se llevaron a cabo iniciativas como la marcha del 1 de mayo de 1996, donde hicieron visible el carácter libertario que configuró ese instante en 1886. En una fecha histórica para el anarquismo, los colectivos anarcopunks se hicieron patentes por primera vez en el espacio de los movimientos de la zona metropolitana

de Guadalajara. Inicia el vínculo con los colectivos simpatizantes del Ejército Zapatista de Liberación Nacional (EZLN).

Desde el levantamiento del EZLN en 1994, el movimiento anarcopunk se encontró con otro, que como él no aspira ni suspira por el poder, que rechaza las vanguardias y los partidos, y tiene como horizonte la autonomía. Nuevamente, como en el siglo xIx y durante la Revolución Mexicana, comenzaron a caminar juntos en un proyecto autonómico los pueblos indígenas y el movimiento libertario. En primera instancia, los colectivos anarcopunks participaron en las actividades para detener la guerra contra las comunidades zapatistas, pero poco a poco se involucraron en las iniciativas político-organizativas generadas por el ezLN: el Frente Zapatista de Liberación Nacional y La Otra Campaña.

Con el colectivo Conciencias Libertarias, concebido en 2003, se retomaron las iniciativas de vinculación con el barrio a través de kermeses, foros y la creación de formas de repeler el hostigamiento cotidiano de la policía, lo cual sigue vigente en barrios como Mesa Colorada, luego de que el colectivo Acción y Conciencia se planteara en 2007 un trabajo de agitación contra la represión y por rehacer los vínculos comunitarios del barrio. El movimiento anarcopunk no es el único que vive la represión en los barrios a través del hostigamiento diario y las revisiones de rutina. El 28 de mayo de 2004 se vivieron momentos de peligro que dejaron presos, golpeados y torturados, mujeres vejadas y una campaña de miedo y xenofobia. La lucha contra la represión de los colectivos anarcopunks, en tanto punto de quiebre para el movimiento, trastocó las formas de hacer política y de organización, pero también el propio horizonte libertario.

Los colectivos Conciencias Libertarias, Sacco y Vanzetti, Resistencia Anti-Tortura Animal y Acción Directa experimentaron formas de solidaridad y de lucha contra la represión que permitieron reflexionar sobre la importancia de que el movimiento se instituya desde espacios y tiempos propios, de la necesidad de crear proyectos y espacios autogestivos situados en 
un lugar-territorio que sirvan como base e impulso, pero también como defensa ante la represión. En 2004 se dejaron de buscar símbolos y representantes de la Sociedad del Poder para ir a confrontarlos, para que la autonomía, como horizonte ético-político, germinara en el día a día de la política organizativa.

Simultáneamente al proceso local, los colectivos anarcopunks de Guadalajara desplegaron intentos de articulación y coordinación en lo nacional e internacional. Desde las Colectividades en 1993 y la Red de Información de Voces Autónomas Libertarias (1997-2001) hasta la Coordinadora Libertaria (2002-2004) se realizaron encuentros para compartir experiencias y saberes, para intentar generar iniciativas conjuntas en todo el país y para crear una organización anarquista de alcance nacional. La Internacional Anarcopunk fue el lugar donde confluyeron los movimientos punks y libertarios de Latinoamérica y España para establecer redes de intercambio y comunicación, así como trabajos que se hacían paralelamente en cada lugar.

No obstante, el movimiento anarcopunk de Guadalajara no es tan visible ahora como lo fue de 1996 a 2004, ni las iniciativas en lo nacional e internacional tienen las mismas características. Las transformaciones en las formas de hacer política, la configuración de un horizonte ético-político de largo plazo y la centralidad que ha adquirido la apertura de espacios-territorio para poner en marcha formas autogestivas de organización y vida son imágenes-testimonios del esfuerzo de este movimiento por estar contra y más allá del Estado y el capital.

\section{VIVIR DESDE EL “¡HAZLO TÚ MISMO!”}

En el movimiento anarcopunk de Guadalajara la vida dentro y consecuente con su horizonte autónomo no pasa sólo por la participación en un colectivo, la práctica política no se reduce a la militancia ni a lo organizativo, sino que tiene que ver también con una forma de sobrevivencia y de relacionarse cotidianamente.
Los saberes, experiencias y formas de hacer, que una buena parte de personas han vivido dentro del movimiento anarcopunk, han permitido crear medios de trabajo autogestivos y relaciones desde la horizontalidad, el apoyo mutuo y la autonomía en el barrio, la escuela, el trabajo y con la comunidad-colectividad. Algo que caracteriza al movimiento libertario de Guadalajara, de varias ciudades del país y de Latinoamérica, es el intento por que los posicionamientos, el hacer y el pensar anarcopunk se realicen en la vida diaria.

Desde el horizonte ético-político anarcopunk se ha logrado romper con una concepción militante y organizativa que caracteriza a los movimientos de izquierda anticapitalistas a lo largo de la historia a la hora de pensar la acción política y los proyectos de autogestión. El punk ha sido capaz de trascender a formas de trabajo autogestivo y cooperativo que hasta ahora se mantienen en la mayoría de los casos como experiencias personales para hacerse de medios económicos para subsistir. Sin embargo, tienen la potencialidad de instituirse como proyectos colectivos que se extienden en los barrios y entre las redes de afinidad y amistad para generar grietastiempos-territorios contra y más allá del Estado y el capital, pues allí se están instituyendo formas no mercantiles y no jerárquicas.

El punto de partida es el rechazo a reproducir la vida en un trabajo formal. Es una postura contra la alienación que se produce cuando el tiempo de vida se reduce a la producción, la circulación y el consumo de las mercancías. De ahí, los propios "haceres" del movimiento anarcopunk se transforman en medios de difusión, comunicación y distribución de la contracultura y el horizonte libertario. La serigrafía, la organización autogestiva e independiente de conciertos - sin patrocinadores, sin policías, con grupos que no pertenecen a disqueras sino que hacen su música desde el "hazlo tú mismo" - el software libre, la construcción de hortalizas para tener control sobre la alimentación, cooperativas de trabajo - café, comida, etc.-, distribuidoras de materiales como discos, fanzines, libros, playeras, permiten dilucidar opciones de 
subsistencia en los márgenes del Estado y el capital. Aunque se trata todavía de experiencias a pequeña escala, no visibles y que no han conseguido trascender a espacios más amplios de la colectividad-comunidad, contienen el proyecto autónomo en germen, pues se instituyen desde una ética no capitalista: en el centro no está la ganancia ni la competencia sino la creación, implica un trato respetuoso con la naturaleza y se niega la reproducción de formas de explotación.

Un lugar creado por el movimiento anarcopunk de Guadalajara con la intención de que se convirtiera en lugar de distribución, pero también de trabajo autogestivo, fue el Tianguis Cultural. En el origen se planteó incluso recurrir al trueque y al intercambio para que no dominara el dinero. En el Tianguis Cultural, tres distribuidoras autogestivas -Estajanovismo Records, Acracia Records y Deserción Distribuye - son una imagen-testimonio de que a través de la serigrafía y la distribución de materiales libertarios se logra vivir bajo otra dinámica de trabajo: ganar lo suficiente para sobrevivir dedicando el menor tiempo posible. Sumado a esto, en el espacio del Tianguis Cultural es común que se recurra a la venta de comida, discos, parches, como una opción de trabajo alternativo, contestatario, como propone Raúl Zibechi.

La promoción-generalización de proyectos autogestivos de vida y su colectivización para que abarquen a más personas del movimiento - también para que se desplieguen en los barrios y se haga resonancia de estas otras formas de vivir y estar al margen- permite que trasciendan los límites del movimiento anarcopunk y que las formas de sobrevivencia y trabajo no dependan sólo de ámbitos como la contracultura. La potencialidad de la hortaliza de Tlaquepaque que algunos miembros del movimiento anarcopunk sostienen y cuidan, el uso y socialización del software libre para no depender de multinacionales y la creación de cooperativas de trabajo de costura, comida, etc., son experiencias en las que ya se están practicando - aquí y ahoraotras relaciones sociales, y por tanto caminan en la

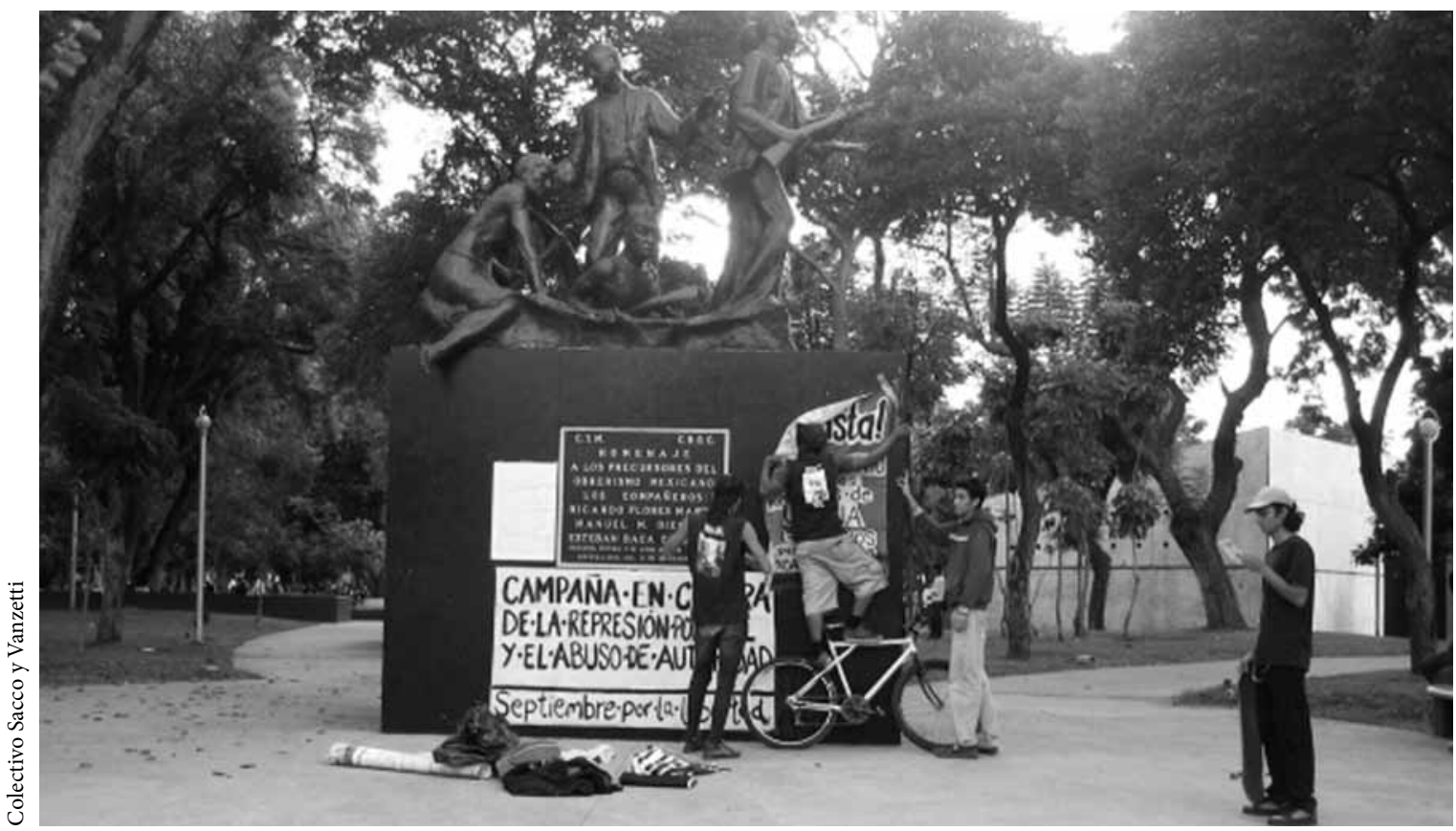

Jornadas contra la represión "Septiembre por la Libertad" organizadas por el movimiento anarcopunk de Guadalajara, Jalisco, 2007. 
perspectiva del horizonte autonómico y libertario, que todavía no da sus frutos porque es de largo plazo y tal vez las personas que trabajan ahora en esta perspectiva no los vean, aunque en un contexto de crisis del capitalismo como el actual cada vez más sujetos sociales optarán por evadir al Estado y el capital para poder existir.

\section{LOS ESPACIOS-TERRITORIOS PARA GERMINAR LAAUTOGESTIÓN}

La otra dimensión desde la que se está nutriendo el horizonte ético-político libertario y punk, además de los modos de trabajo autogestivo, es la creación de espacios del movimiento: territorios en los que se sitúe la historia, desde los que se creen medios de autodefensa contra la represión, donde se vivan otras relaciones sociales y que signifiquen la base donde se sostengan los proyectos autónomos. Para el movimiento anarcopunk de Guadalajara, las calles son el primer espacio que se ocupa y al que se le da significado, se vive como una zona temporalmente autónoma, como lo llamó años después Hakim Bey. A la esquina, al baldío, después a la bodega, al parque y a la casa se les da contenido. A estos espacios los instituyen tiempos vividos de ruptura.

En un inicio, los espacios-territorios significaron el lugar donde se creaban y reproducían las relaciones de afinidad, amistad y apoyo mutuo: la convivencia en la que ocurre el intercambio de saberes y se forjan las complicidades para hacer $y$ construir en común, primero la contracultura punk, después una constelación de este imaginario con el horizonte libertario. Esto planteó la necesidad de ocupar parques, quitar los espacios públicos del control de la policía y los gobiernos, para significarlos por unos instantes desde una perspectiva autónoma. El Parque Revolución-Rojo, la Pila Seca en Tlaquepaque, la propia Plaza Juárez durante el Tianguis Cultural, se transformaron en espacios de organización, adquirieron una historia a partir de las iniciativas y discusiones que ahí se generaban, pero también se les vertió toda la historia del movimiento libertario.

Sin embargo, la calle y los espacios públicos implicaban fragilidad, dejaban al movimiento anarcopunk de Guadalajara expuesto a la represión desde que el movimiento comenzó a generar iniciativas de confrontación con el gobierno, repeliendo el hostigamiento policiaco, defendiendo el Tianguis Cultural, participando con otros colectivos en las iniciativas zapatistas del EzLN y haciendo actividades contra las multinacionales y por la liberación animal. De ahí la necesidad de que ese espacio-territorio tomara la forma de una casa. Después de la represión de 2004, una de las primeras tareas del movimiento anarcopunk para volver a situarse desde sus tiempos y espacios fue la construcción de un centro social. Esta primera experiencia, de finales del 2004 a principios de 2005, aunque no se convirtió en un lugar concreto, permitió imaginar lo que se quería construir. Sirvió de ruta para que un año después se creara la Cooperativa de Trabajo Autogestivo Regeneración, la cual intentó conjuntar la forma-centro social con el intento por crear medios de trabajo alternativos como los que se desarrollan en lo individual, pero involucrando a la colectividad que se encargaba de sostener la casa.

Este proyecto duró más de dos años, sirvió como un espacio de encuentro y convivencia, sustituyendo a los parques que el movimiento anarcopunk ya no mantuvo ocupados. Una pluralidad de iniciativas destinadas a la difusión del horizonte libertario y su historia, pero también para el proceso político organizativo del movimiento de Guadalajara, se hicieron patentes. Surgieron intentos por consolidar formas de auto-empleo con una perspectiva autogestiva -haciendo pan, serigrafía y una cocina comunitaria-, se planteó un proceso de auto-formación política a través de la instalación de una biblioteca y de círculos de estudio.

La Cooperativa Regeneración acumuló una pluralidad y heterogeneidad de saberes que dieron sostén al proyecto que promueve actualmente un colectivo, llamado Grupo Libertario Solidaridad, 
parte del movimiento anarcopunk de Guadalajara: el Centro de Estudios y Documentación Anarquista (CEDA) "Francisco Zalacosta". Este local mantiene el sentido de instituirse como un espacio-territorio que se signifique como un lugar de encuentro y sirva para que se potencien otros individuos y colectivos del movimiento anarcopunk. Se constituye como una iniciativa que favorece procesos de autoformación política a través de una biblioteca, círculos de estudio, foros y pláticas. En el horizonte de mediano plazo trabaja por la construcción de un espacio común de organización y lucha del movimiento anarcopunk, desde el que se reconstruyen las formas de hacer política. Desde el CEDA "Francisco Zalacosta" se imagina y se dilucida un espacio-territorio con la potencialidad de generar formas de trabajo autogestivas que abarquen a la comunidad anarcopunk y que hagan resonancia en sus barrios, escuelas y centros de trabajo.

La imagen-testimonio que nos muestra el movimiento anarcopunk de Guadalajara hace referencia se ha planteado estar al margen de los tiempos-espacios del Estado y el capitalismo como necesidad política. Podríamos decir - si lo situamos dentro de la historia del movimiento anarquista, como los propios sujetos se reconocen- que es un pensar y un hacer que se han propuesto la creación de una sociedad auto-organizada de modo horizontal y federativo mediante formas de acción directa y asamblearias durante más de 150 años. El movimiento puede resultar una imagen-testimonio pequeña, apenas visible y tal vez insignificante para la capacidad de dominación, explotación, despojo y represión del Estado y el capital, pero todo sujeto individual y colectivo que diga no y que genere formas de insubordinación crea grietas en la dominación, en la sociedad dividida entre dirigentes y ejecutantes; pone en cuestión toda la dominación pasada y presente en tanto contienen temporalidades revolucionarias y de emancipación latentes, que al estar-ser en colectivo, instituyéndose como conflicto social, genera las crisis en la reproducción del capital y crisis de dominación en los Estados. 